\title{
Assembling New Toolboxes of Methods and Theories for Innovative Critical Research on Educational Technology
}

\author{
Linda Castañeda ${ }^{1}\left(\mathbb{C}\right.$ and Ben Williamson ${ }^{2} \odot$ \\ ${ }^{1}$ Department of Didactics and School Organization, Universidad de Murcia, Spain \\ ${ }^{2}$ Centre for Research in Digital Education, University of Edinburgh, United Kingdom
}

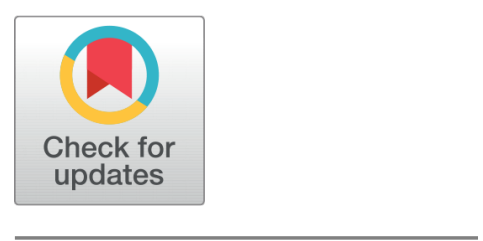

Received 2020-12-28

Revised 2020-12-29

Accepted 2020-12-30

Published 2021-01-15

Corresponding Author

Linda Castañeda,

lindacq@um.es

Facultad de Educación. Campus de Espinardo, 30100 Murcia (Spain)

DOI https://doi.org/10.7821/ naer.2021.1.703

Pages: 1-14

Distributed under

Creative Commons CC BY 4.0

Copyright: (C) The Author(s)
Keywords EDTECH CHALLENGES, RELATIONAL RESEARCH, COMPLEX RESEARCH, EDUCATIONAL TECHNOLOGY, RESEARCH METHODS

\section{INTRODUCTION}

The experience of the COVID-19 pandemic has brought educational technology (edtech) to greater public attention and reinvigorated critical academic scrutiny. Many of the concerns highlighted to mainstream educational audiences (educators, managers, parents, politicians, general public) during the pandemic mirror problems already raised in previous research (Castañeda \& Selwyn, 2018; Williamson, Eynon, \& Potter, 2020). Certain developments and issues associated with edtech have been amplified and intensified, however, and the outlook for the rest of the 2020s suggests edtech is likely to continue growing in significance (pedagogically, politically and economically), while also generating new controversies and evolving in ways that remain hard to foresee (Selwyn et al., 2020).

One immediate tension likely to shape edtech use in the immediate post-pandemic context is between techno-utopian edtech enthusiasts that saw the pandemic as a 'great experiment' and an opportunity to accelerate the 'digital transformation' of education for the future, and critical voices that deemed 'emergency remote teaching' to be a disaster -a position problematically tangled up with politicized debates about returning students to school rather than learning online, despite the public health risks (Williamson \& Hogan, 2020). As in the past, neither of these binary positions on edtech is likely to offer a constructive path forward (Reich, 2020). Edtech and online learning cannot be seen simply in terms of their 'enhancement' effects on teaching and learning, nor only in strongly political terms as a risk or threat to students, schools and universities (Anderson \& Rivera-Vargas, 2020; Hamilton \& Friesen, 2013). Any analysis of edtech needs to acknowledge how it is embedded in sprawling educational issues that go beyond the idea of a particular type of pedagogy or set of school practices to complex relationships with technology development, business, economics and politics, as well as to individual behaviours, bodies, physical settings and local cultures, which require similarly complex analysis (Castañeda, Salinas, \& Adell, 2020; Castañeda \& Selwyn, 2018).

\section{OPEN ACCESS}


This special collection is animated by our shared interests and concerns in the direction of educational technology research in these shifting circumstances. Our first concern is that certain branches of education in general, but especially in edtech research, are continuing to seek out evidence of 'what works' in relation to the application of specific edtech applications (Lai \& Bower, 2019; Zhao, 2017). Such studies may be so profoundly dedicated to research questions about technological effects that they bypass the crucial educational questions (Bartolomé, Castañeda, \& Adell, 2018; Zawacki-Richter, Marín, Bond, \& Gouverneur, 2019), or so focussed on learning sciences methodologies and explanations - privileging psychological, cognitive and neuroscientific understandings of learning - that they neglect the complex social, political, economic and technical factors that shape individual and collective experiences and outcomes in education (Kirschner \& Kester, 2016). In some cases, edtech research tends towards an 'engineering' vision of how to fix education with advanced technologies, as indicated by the emergence of discourses of 'learning engineering' or 'precision education' (Bartolomé, Rodriguez-Illera, \& Lindín, 2018; Williamson, 2020). The production of learning science-based edtech effects evidence is also being elevated by new kinds of industry-led alliances and funders, and is not without its own politics (Ames, 2019; Perrotta, Gulson, Williamson, \& Witzenberger, 2020).

The second concern is that specifically 'critical' edtech research may need to evolve fast in order to both interrogate contemporary shifts in edtech with adequate nuance and depth, and to develop constructive responses/proposals to the wider field of edtech research especially given recent experiences with online education (Bayne et al., 2020). Our aim is certainly not to set up a false sense of conflict between different branches of edtech research. Instead, it is to highlight the necessity of complicated and nuanced approaches to edtech that see it as inseparable from socially-embedded human bodies or internal or distributed learning processes, as well as intricately tangled up in social, economic, cultural, political and technical contexts.

Some of our inspiration in compiling this issue is from recent theorizing of 'postdigital' education, which collapses distinctions between analogue, digital, biological and material forms (Jandrić et al., 2018), studies of educational digital infrastructures and information networks (Sellar \& Gulson, 2019), research on educational 'policy mobilities' (Lewis, 2020) and 'policy assemblages' (Savage, 2020), 'biosocial' analyses of learning as both biologically embodied and socially embedded (Youdell \& Lindley, 2018), and rich bodies of scholarship in 'digital sociology' (Marres, 2017), 'platform studies' (Dijck, Poell, \& Waal, 2018), 'software studies' (Kitchin \& Dodge, 2011), and 'critical data studies' (Bigo, Isin, \& Ruppert, 2019). Across these diverse bodies of scholarship, we see sustained attention to ideas of dynamism, movement, complexity, interconnectedness, mutation, and concepts including assemblage, sociomaterialism, relationality, processuality and performativity. Many of these approaches and related concepts appear in the papers collected in this special issue.

In calling for 'critical' approaches to edtech, then, we mean studies that adopt such dynamic and complicated perspectives, rather than studies animated by militant critical activism and resistance. There are certainly edtech applications that may demand a more resistant activist response, but that too is part of the more complicated approach we are 
advocating. Controversies, protests and legal action over exam proctoring technologies during the pandemic, for example, illustrate that edtech exists in contexts that are marked by disagreement and conflict rather than being neutral tools for deployment in decontextualized settings. Those protests and controversies are interesting themselves but are particularly relevant if they invigorate fundamental public discussions (and research debates) about the nature of education, teaching, learning and their knotty, context-sensitive, and sometimes highly contested relationships with digital technologies.

One of the key arguments running through the papers in this special collection is that edtech needs to be understood relationally. This means edtech cannot be understood simply in terms of technological tools that produce effects, as in crude, essentialist forms of technological determinism, or as 'mere tools' that people mould and put into service for their purposes, as in some instrumentalist and social deterministic perspectives. Rather, from a relational perspective, we can appreciate that edtech, to be contextually produced, distributed and used; interacts with bodies and behaviours; is used differently in highly diverse situated settings; carries the imprint of its producers' business plans and objectives; is caught up in (trans)national policy agendas and geopolitics; requires funding and investment from financial sources; emerges from specific practices of R\&D conducted in different software studios or research labs; is marketed to schools and universities in new global marketplaces; is inspired -explicitly or not- by certain theories or assumptions about pedagogy, education or learning; generates various forms of evangelism, accommodation, caution, non-use or outright rejection; is entangled in ethical challenges and questions over fundamental rights to education; surfaces profound contests over the claimed purposes and values of education; and much more.

In calling edtech complicated and relational, we are calling for research that takes seriously the various relations through which edtech comes into being and is used.

The aim of this special collection is to highlight fresh directions for specifically critical, complex, social scientific studies of edtech. Given its emphasis on relationality and assemblages, we think of the special collection as part of a process of assembling a new toolbox of methods and theories for critical edtech research. In order to open up discussion on these potential trajectories, the authorship teams in this collection include researchers who acknowledge the past history of methodological and theoretical inquiries into edtech but are also developing new methodological and theoretical repertoires that are appropriate to an evolving and mutating edtech context. We will not rehearse the papers in this paper, instead offering an overview of emerging issues and challenges that we believe help clarify and substantiate our call for more complex relational studies of edtech and introducing some of the innovative theoretical and methodological approaches highlighted across the collection. 


\section{EMERGING ISSUES AND CHALLENGES IN EDTECH RESEARCH}

Although some learning science-based research on edtech and the commercial sector of edtech suppliers tend to focus on the point of interaction between instruction and technology and the results of that encounter, a more relational approach to edtech requires research that takes a broader perspective. In this section, we highlight some emerging issues and challenges that edtech research is only just beginning to unpack, and which raise questions about the kinds of theoretical toolboxes, analytical frameworks and methodologies required for such studies.

\subsection{New Edtech Actors}

The field of educational technology has always been rather a complicated one, involving a diverse mix of academic learning scientists, educationalists, instructional designers, educational technologists, managers, and commercial companies. However, the ecosystem of edtech development has become increasingly complex, networked and multisectoral in recent years. Organizations and individuals working at multiple scales from the macro-level transnational policy context, to meso-level commercial companies working in national settings, to micro-level teacher specialists in specific schools and classrooms (some of them with extensive social media audiences and influence in the day to day classrooms) are among the immensely diverse inhabitants of the emerging edtech ecosystem. In much the same way that the role of networks and entrepreneurs can change how specific educational policies are disseminated, translated, and materialized, or inflected, mediated, resisted, or misunderstood (Ball, 2013), the role of new edtech actors can affect edtech discourses, practices and policies too (Honan, 2010; Player-Koro, Rensfeldt, \& Selwyn, 2018).

Some of the new actors in the edtech ecosystem remain significantly under-researched and weakly conceptualized in critical edtech studies. An initial list of new edtech actors would include technology investors and edtech market intelligence agencies, which apply complex financial techniques and practices to the valuation of edtech markets and investment in edtech companies (Regan \& Khwaja, 2019). Technological companies are creating new forms of technology-based learning institutions that promise to achieve goals that traditional educational institutions full of people cannot do, even if the experiments of those new institutions just fleetingly survive, fail, or pivot to become conventional online programme management providers (e.g. AltSchool, MissionU, Knewton).

Teacher influencers, edtech ambassadors and evangelists, often active on social media, act as new kinds of intermediaries between edtech businesses and practitioners, offering advice, guidance and leadership through seemingly bottom-up social and professional networks. Some of these influencers act as brand ambassadors for either edtech companies or for the educational divisions of multinational technology corporations (e.g. Microsoft, Google), and others are able to craft their own branded identities as tech experts and practitioner-consultants with careers that appear closer to social media influencers and YouTube celebrities than classroom practitioners. Teachers can also create, exchange and 
sell curriculum and pedagogic resources on sites such as Teachers Pay Teachers, Amazon Ignite and Course Hero, becoming micro-entrepreneurs and enterprising professionals in new teaching resources marketplaces.

Selected institutions may even become edtech 'demonstrator schools', while large edtech industry trade events have the function of selling technology to school IT administrators. Within schools and universities, new roles have opened up for system administrators, data managers, analysts and so on, with professional responsibilities that include edtech procurement, infrastructure maintenance, ethical and legal compliance, data analytics and reporting. These roles all require new forms of expertise, knowledge and professionalism, and demand continuous training, upskilling and professional development as educational institutions become increasingly interwoven in complex interoperable systems of management, administration and educational technology.

New edtech evidence organizations and alliances have also appeared. Such groups are seeking to produce highly standardized criteria for the evaluation of edtech effectiveness and efficacy, as a way of supporting the procurement decision-making of schools and universities. For example, the Edtech Evidence Exchange is an alliance that will produce evaluation standards and a platform for school leaders to access data on 'what works where, and why' for edtech decision-making (https://edtechevidence.org/edtech-genome-project). Support for such initiatives and for the edtech more broadly is coming from international organizations including the World Bank and World Economic Forum, which see edtech as central to securing the technical skills and talent for the 'Fourth Industrial Revolution'.

Edtech is also being supported and funded by highly influential technology figures, particularly through their personal philanthropic and investment vehicles. Facebook founder Mark Zuckerberg's Chan Zuckerberg Initiative (CZI), for example, funds the Edtech Evidence Exchange. Funders and policy influencers like CZI are also supporting innovative new learning sciences approaches to the measurement of cognitive and brain-based learning processes, including agendas such as 'learning engineering ' - mentioned above- and the use of biosensors and neurotechnologies for student assessment. While the Gates Foundation has been active in education for decades, CZI and Schmidt Futures - the philanthropic and investment initiative of ex-Google chief executive and chair Eric Schmidthave become generous donors to edtech startups and technology-based initiatives, as well as investors in profit-making edtech companies and powerful, politically-connected lobbyists for tech-based educational transformation. Reed Hastings of Netflix has established an educational training retreat, Peter Thiel of PayPal and Palantir established an alternative model to higher education, Tesla founder Elon Musk set up a secretive school called Ad Astra within the SpaceX programme, and Amazon's Jeff Bezos has begun establishing a network of Bezos Academy pre-schools too. Technology wealth and power is now playing an important role in establishing visions of the future of technology-intensive education.

Importantly, many of these actors are also increasingly networked in multisector webs that gives them greater power and influence across policy and practice settings. Notably, during the COVID-19 pandemic, a number of large networks formed to promote edtech solutions to school and campus closures, with organizational participants ranging from 
UNESCO and the OECD to Google and Microsoft. These examples give some sense of the expanding ecosystem of actors that are associated with edtech beyond the pedagogical practices, including huge transnational organizations, and the ways that edtech has become a significant area of commercial business, market investment, and policy intervention.

\subsection{Expanding Scale and Reach}

A second related key issue is the rapidly expanding scale and reach of educational technologies. Global technology companies such as Microsoft and Google have for many years, of course, acted as large-scale suppliers of educational hardware and software. The scale of their operations has grown substantially as they have become worldwide providers of digital infrastructure for schools, including in low and middle-income countries. This scaling-up of 'Big Tech' into schools was amply illustrated in 2020 by Google's claims to have reached well over 100 million student users across the planet, as national government ministries of education and transnational organizations alike supported the roll-out of platforms such as Google Classroom as online replacements for the physical classroom during school closures (Perrotta et al., 2020).

In the higher education sector, the reach of edtech into new institutional settings and teaching practices has been promoted as part of a 'digital transformation' agenda, with significant support from multinational consultancies and think tanks such as Deloitte and McKinsey as well as local and national agencies and government departments. In the UK, for instance, the HE sector's digital learning agency Jisc launched a major Reimagining Teaching and Learning programme in 2020 to scale up the use of edtech in universities. Part of the initiative includes supporting UK-based edtech startups by matching them to institutions to develop intensive problem-solving collaborations. More broadly it calls for university leaders to adopt the same design principles as some of the world's most successful technology and platform companies, such as Amazon and Netflix, in order to transform their 'digital infrastructure' and remain competitive in a post-pandemic context of financial instability (https://www.jisc.ac.uk/guides/digital-strategy-framework-for-univers ity-leaders). Obviously, there are other approaches to this digital escalation in HE (e.g. the Enhancing Digital Teaching \& Learning in Irish Universities Project https://edtl.blog), some of them, focussed on education, students, school management or governance and not only in entrepreneur management. Nevertheless, research on these large-scale strategic projects remains scarce, as well as being methodologically and conceptually challenging.

Another significant way the reach and scale of edtech are expanding is through the development of a direct-to-consumer edtech business model. Particularly in the context of COVID-19, many edtech companies realized the potential market opportunities available from selling their products directly to parents or students. In China, the home tutoring platform Yuanfudao, for example, received two of the largest ever investments in the edtech industry worldwide in 2020 alone, taking its total market value to more than USD \$15billion and making it the most valuable edtech company on the planet. Amid widespread anxiety about 'learning losses' incurred during the pandemic, edtech companies promise to provide a new form of private supplementary tutoring and 'catch-up' services, often by deploying so- 
called AI technologies for 'personalized' tutoring. As such, edtech has expanded its reach beyond the institutional enclosures of schools and colleges to enter students' homes in the shape of a 'shadow education industry' of automated robot teachers.

Edtech has also expanded to the geopolitical domain, with nations and global regions seeking to harness edtech to the development of 'human capital' and economic advantage in increasingly digital economies (Knox, 2020). In India, for example, the National Education Policy 2020 framework states that 'New technologies involving artificial intelligence, machine learning, block chains, smart boards, handheld computing devices, adaptive computer testing for student development, and other forms of educational software and hardware will not just change what students learn in the classroom but how they learn' (Government of India, 2020, p. 54). It also highlights the need for AI education to enable India to become a 'digital superpower'. Likewise, the European Parliament has begun considering a resolution on $\mathrm{AI}$ in education, highlighting how 'AI is transforming learning, teaching, and education radically', most notably through the potential of 'personalised learning experience' made possible by the collection, analysis and use of 'large amounts of personal data' (European Parliament, 2020, p. 7). As these examples indicate, edtech has become a major focus of education policy and considered a source of potential geopolitical advantage by 'upskilling' students for productive performance in digital economies. This argument is supported by transnational organizations such as the OECD, World Bank and World Economic Forum. Increasingly, it seems, states are calculating the potential return on investment that edtech promises in terms of producing 'human capital' for global competition in the post-pandemic economy.

\subsection{New Technical Capacities and Expertise}

The third significant set of challenges relates to the emergence of new technical capacities and forms of expertise. Many edtech applications have absorbed the underlying technologies and formats of the wider global technology industry. Rather than being packaged up as school software, edtech comes as apps and platforms, often able to be integrated through application programming interfaces (APIs) to permit the flow of data. Increasingly, single edtech applications are thoroughly entangled in webs of programs, apps and platforms, and plugged in to interoperable infrastructures for seamless and frictionless learning experiences. Many of the world's largest technology companies now market cloud computing and digital infrastructure to both the schools and higher education sectors, such as Amazon Web Services cloud and machine learning services for education, Microsoft educational infrastructure, platforms and apps, Google G Suite, and the Salesforce Education Cloud. These systems promise to integrate the physical infrastructures of education -campuses, buildings, classrooms, hardware - with new digital infrastructures, and open up the possibility of long-term dependencies of public education institutions on global private technology companies, and new technological lock-ins to proprietary systems.

Another major development in the edtech field is 'datafication' and the capacity to generate fine-grained, historical and real-time digital information about people's participation in educational processes (Brown, 2020; Jarke \& Breiter, 2019; Livingstone, Stoilova, 
\& Nandagiri, 2020). In the case of students, most data are focussed on collecting and use data about student performance, often twinned with techniques of personalization to customize educational materials to the individuals. Staff performance data may also be collected directly, or by proxy from calculations of student outcomes and progression and used as potential decision-making tools about professional teachers' careers (Adell, Castañeda, \& Esteve, 2018; Holloway, 2020). Datafication depends on complex underlying technologies of data analytics, cloud computing and data infrastructures, as well as the machine learning, neural networks and deep learning techniques that power contemporary artificial intelligence (Knox, Williamson, \& Bayne, 2020).

The application of such technologies in education raises a host of new issues and challenges: potential for algorithmic discrimination based on biased training datasets, enhanced surveillance and monitoring, erosion of privacy, and reductionist ways of understanding students' learning, educational processes dynamics and development. On the other hand it raises the importance of innovative educational approaches that take all of this into account, and that improve students and teachers data understanding to empower them (Harrison et al., 2020; Loftus \& Madden, 2020).

In terms of expertise, the new technical capacities of edtech require new kinds of experts and professionals with distinctive forms of knowledge and practice. Education data scientists, learning analytics specialists and even learning engineers bring novel approaches to analysis and knowledge production in education (Williamson, 2020). These specialist positions may be located in university schools of education or computer science departments, government ministries or commercial businesses. To a significant extent, the combination of data science technologies and methodologies may even be changing the ways that complex processes such as learning, cognition, and other educational outcomes are understood and assessed, as data analytic techniques of pattern recognition, clustering and prediction become central to the production of new knowledge in the field of education. Moreover, the increasing datafication of education also brings new financial actors and techniques into play, such as those who can transform data into 'assets' and secure profitable 'rent' from their ownership and control (Komljenovic, 2020). But at the same time, capacities of other educational specialists (educators, educationalists, managers, tutors, counsellors, etc.) are challenged. They must evolve, not just to use technology to do their job, but to respond reliably to the new situations promoted by edtech and are encouraged to share and reproduce edtech-based visions of the future of education in their own working practices.

\section{INNOVATIVE CONCEPTS, THEORIES AND METHODS IN EDTECH RESEARCH}

The selection of challenges above illustrates some of the ways that educational technology, understood not only as a research field but also as an industry, is mutating and evolving, in ways which we believe demand new kinds of critical responses and empirical examinations by social scientific researchers in education. Across the papers in this special collection, authors have sought to develop a range of new theoretical positions, analytical concepts 
and methodological frameworks for the critical study of educational technology.

Much of the work to be done is related to reshaping some of the central terminology and conceptual frameworks that characterize edtech research (Hannon \& Al-Mahmood, 2014), including the review of 'Educational Technology' as a disciplinary term (Castañeda et al., 2020). Once such terms become ubiquitous and for those using them, they can tend to become imprecise and redundant categories. Edtech, as we have illustrated already, exceeds its own categorization, with researchers now confronted with a bewildering constellation of organizational types, human experts, diverse technologies, business models, R\&D procedures, geopolitical contexts, and (trans-)national policy agendas. Given this complexity, referring to educational technology terms through superficial definitions of technological aspects or common elements is a problematic grounding for any meaningful analysis. A good example is offered by various reviews of the term digital competence, and very especially the digital teacher's competence (Castañeda, Esteve, \& Adell, 2018). Responding to this definitional imprecision (Pangrazio, 2021), conceptualizes three terms related to how individuals learn to live in digital mediated societies': citizenship, literacy and rights. Her objective is precisely clarifying them, complexly and relationally, to 'activate' them for productive research.

One emerging thrust of research on educational technology has sought to adopt some of the conceptual and methodological frameworks from social science fields of science and technology studies (STS), digital sociology, and other related approaches in geography, history, anthropology, and philosophy of technology. This has led to a burgeoning body of work which takes seriously the social and technical production of edtech, and the productivity of edtech to produce both intended and unintended effects where it is put to use. Studies in this vein seek to unpack what edtech is made of, how it is made and for what purposes or aims. This means approaching edtech in many different and complementary ways. As the complex end-product of various social and technical practices of writing computer programs, developing business plans, arranging project management plans, product testing, generating funding and so on, all of which takes place in organizations, among professionals with different forms of expertise. It also means inquiring into the actual underlying technologies of edtech, such as the specific kinds of algorithms or data architectures that any single application depends on. Beyond that, such inquiries also seek to uncover the embedded assumptions that underpin edtech development, such as specific theories about learning, teaching and education in general; the commercial ambitions that galvanize them; the political and ideological commitments of their producers and their implementers; and even the governmental or policy agendas to which they respond. As this all indicates, edtech needs to be understood in relational terms as the result of myriad intersecting social and technical elements.

Perrotta (2021) refers to the STS principle of 'underdetermination' to counter the technological determinism that has characterized significant bodies of educational technology research and development. As Perrotta argues, 'edtech determinism' assumes that there are observable causal relations between tools, devices, platforms, computers on the one side and cognitive and behavioural outcomes on the other. In contrast, research informed by 
the principle of underdetermination assumes that social, scientific and technological phenomena cannot be reduced to linear relationships between antecedents and consequences but are in fact the complex results of constellations or 'assemblages' of social and material influences. Taking up the concept of underdetermination therefore opens up edtech to a range of cultural, social and political analyses that are attentive to the ways various relations between actors, objects, technologies and policies have to be assembled in the production of edtech, and how other complex relations in combination shape the ways that edtech is taken up and used in concrete practices. The contributions to this special issue amply substantiate and illustrate such approaches.

Also rooted on anthropological research approaches, and shifting the perspective to relational ontologies, an important theoretical development in recent critical research on educational technology is the turn to sociomaterial conceptualizations. Sociomaterialist studies propose that all aspects of digital engagement are in fact grounded in material and embodied entanglements with devices and other artefacts (Fenwick, Edwards, \& Sawchuk, 2011). One key move in sociomaterial studies of edtech is to grapple with the materiality of edtech itself (Gourlay, 2021). Rather than being 'virtual' or 'immaterial', all digital technologies are in fact constituted from material objects such as computer chips, hardware, cables, and various minerals, polymers and chemicals. Moreover, digital practices are often considered disembodied and separate from social and physical conditions and contexts, which, Gourlay argues, obscures the very real physicality of devices and the materiality of the social contexts in which digital engagements take place. As Carvalho and Yeoman (2021) argue, a 'physical' learning space is likely to involve a range of technologies and in addition to paying attention to these 'technologies' one must understand and account for their physical sites of use too. The social, technical and material are not separable but continuously overlapping and interpenetrating in educational uses of technology.

Sociomaterial approaches open up rich possibilities for research, but also demand new kinds of methodologies. Decuypere (2021) offers a methodological approach termed 'social topology'. Referring specifically to processes of datafication through the generation of discrete data points within complex data infrastructures or information systems, Decuypere approaches the 'data practices' associated with edtech as relational assemblages. The relational-topological toolbox he proposes is intended to open up the 'black box' of data practices to empirical analysis. From a social topological perspective, data practices are performed and enacted in concrete sociomaterial settings, through specific kinds of devices that continually put data together in various and constantly changing ways and forms. Topological methodologies investigate how data practices are constructed and come into being — not just what relations actually are present, but how those relations are formed, sustained, or fragment and fall apart. As such, a social topological approach to edtech might investigate various different objects and relations, such as those that occur between single interfaces, user interactions, technical design and programming, and their wider ecologies. This approach opens up multiple innovative ways into the study of edtech. 


\section{AND NOW?}

This collection is a part of a promising toolkit and a compilation of exemplars for research on educational technology over the coming years. Our intention was to highlight some innovative ways in which theory and method are being developed, and to broaden the scope of edtech research to encounter the relational constellations of elements and activities involved in its development, promotion and uses. Although this is clearly not an exhaustive toolkit, it highlights some important directions for future studies on the range of actors, technologies, practices, settings and relations that constitute contemporary edtech. We hope that critical social science-oriented researchers of edtech continue to develop new methods and rework their theoretical frameworks, possibly even by employing digital technologies as part of their methodological approach (Davies, Eynon, \& Salveson, 2020). Other researchers will continue assembling the necessary theoretical and methodological toolboxes required to examine educational technology as they continue to mutate, evolve, extend to new settings and expand in their (un)intended uses.

Nevertheless, there remain many issues to be addressed. The sociomaterial perspectives, new topologies and relational ontologies of edtech articulated in the papers all raise challenges regarding our relationships with machines, their role in education, and ethical questions about how they are integrated and what social, labour and integration decisions they require us to make. How, in addition, can the kind of evidence produced through relational analyses be translated to support teachers and other practitioners to rethink the ways that edtech works in their institutions and classrooms? There are lingering questions here, too, about how teachers might be involved in difficult debates about the social and political significance of edtech, for example if automation impacts on labour conditions or 'redlines' students' access to educational materials.

Given the uneven and unequal effects of the COVID-19 pandemic on students around the world, how can we address urgent questions about edtech and social justice, particularly as multinational companies and intergovernmental organizations promote edtech as a postpandemic equalizer of educational opportunities and outcomes? Additionally, the complex, relational, sociomaterial approaches highlighted in this collection need to be understood as the products of particular advantaged research settings in Europe, north America and Australia. Edtech research stands to benefit from advancing globally diverse voices and approaches, especially in order to enrich context-specific understandings of edtech and practices in local settings. On this last point, relational approaches to edtech research cast doubt on the imposition of 'what works' edtech strategies, which rest on the assumption of cross-cultural relevance and appropriateness and the evaluative criteria of organizations located in the global north. If edtech research in the post-pandemic 2020s is to have a social and political role, it might be to propel more globally diverse voices in setting alternative agendas for educational technology than those that originate in either bureaucratic offices or education technology development studios. 


\section{REFERENCES}

Adell, J., Castañeda, L., \& Esteve, F. (2018). ¿Hacia la Ubersidad? Conflictos y contradicciones de la universidad digital. RIED. Revista Iberoamericana de Educación a Distancia, 21, 51-51. https://doi.org/10.5944/ried.21.2.20669

Ames, M. G. (2019). The Charisma Machine: The Life, Death, and Legacy of One Laptop per Child. MIT Press.

Anderson, T., \& Rivera-Vargas, P. (2020). A Critical look at Educational Technology from a Distance Education Perspective. Digital Education Review, 0(37), 208-229. https://doi.org/10.1344/ der.2020.37.208-229

Ball, S. (2013). The education debate. Policy Press.

Bartolomé, A., Castañeda, L., \& Adell, J. (2018). Personalisation in educational technology: the absence of underlying pedagogies. International Journal of Educational Technology in Higher Education, 15(1). https://doi.org/10.1186/s41239-018-0095-0

Bartolomé, A., Rodriguez-Illera, J. L., \& Lindín, C. (2018). Una 'educación’ en manos de ingenieros. In T. Lleixá, B. Gros, T. Mauri, \& J. L. Medina-Moya (Eds.), Educación 2018-2020 (pp. 13-18). Institut de Recerça en Educació.

Bayne, S., Evans, P., Ewins, R., Knox, J. L., Macleod, H., Shea, C., ... Sinclair, C. (2020). The Manifesto for Teaching Online. MIT Press.

Bigo, D., Isin, E., \& Ruppert, E. (2019). Data Politics: Worlds, Subjects, Rights. Routledge.

Brown, M. (2020). Seeing students at scale: How faculty in large lecture courses act upon learning analytics dashboard data. Teaching in Higher Education, 25(4), 384-400. https://doi.org/10 .1080/13562517.2019.1698540

Carvalho, L., \& Yeoman, P. (2021). Performativity of materials in learning: The learning-whole in action. Journal of New Approaches in Educational Research, 10(1), 28-42. https://doi.org/ 10.7821/naer.2021.1.627

Castañeda, L., Esteve, F., \& Adell, J. (2018). ¿Por qué es necesario repensar la competencia docente para el mundo digital? . RED. Revista de Educación a Distancia, 56. https://doi.org/10.6018/ $\mathrm{red} / 56 / 6$

Castañeda, L., Salinas, J., \& Adell, J. (2020). Hacia una visión contemporánea de la Tecnología Educativa. Digital Education Review, 0(37), 240-268. https://doi.org/10.1344/der.2020.37 .240-268

Castañeda, L., \& Selwyn, N. (2018). More than tools? Making sense of the ongoing digitizations of higher education. International Journal of Educational Technology in Higher Education, 15(1). https://doi.org/10.1186/s41239-018-0109-y

Davies, H. C., Eynon, R., \& Salveson, C. (2020). The Mobilisation of AI in Education: A Bourdieusean Field Analysis. Sociolog, December. https://doi.org/10.1177/0038038520967888

Decuypere, M. (2021). The topologies of data practices: A methodological introduction. Journal of New Approaches in Educational Research, 10(1), 67-84. https://doi.org/10.7821/naer.2021 .1 .650

Dijck, J. V., Poell, T., \& Waal, M. D. (2018). The Platform Society: Public Values in a Connective World. Oxford University Press.

European Parliament. (2020). Draft report on artificial intelligence in education, culture and the audiovisual sector (2020/2017(INI)). Retrieved from https://www.europarl.europa.eu/doceo/ document/CULT-PR-655862_EN.pdf

Fenwick, T., Edwards, R., \& Sawchuk, P. (2011). Emerging Approaches to Educational Research: Tracing the Socio-Material. Routledge.

Gourlay, L. (2021). There Is No 'Virtual Learning': The Materiality of Digital Education. Journal 
of New Approaches in Educational Research, 10(1), 1-10. https://doi.org/10.7821/naer.2021.1 649

Government of India. (2020). National Education Policy 2020. Retrieved from https://nenow.in/ wp-content/uploads/2020/07/NEP-final-for-circulation.pdf

Hamilton, E., \& Friesen, N. (2013). Online Education: A Science and Technology Studies Perspective / Éducation en ligne: Perspective des études en science et technologie. Canadian Journal of Learning and Technology / La revue canadienne de l'apprentissage et de la technologie, 39(2). https://doi.org/10.21432/t2001c

Hannon, J., \& Al-Mahmood, R. (2014). The place of theory in educational technology research. Rhetoric and Reality: Critical Perspectives on Educational Technology: Proceedings of the 31st Annual ASCILITE Conference (pp. 745-750).

Harrison, M. J., Davies, C., Bell, H., Goodley, C., Fox, S., \& Downing, B. (2020). (Un)teaching the 'datafied student subject': perspectives from an education-based masters in an English university. Teaching in Higher Education, 25, 401-417. https://doi.org/10.1080/13562517.2019 .1698541

Holloway, J. (2020). Teacher accountability, datafication and evaluation: A case for reimagining schooling. Education Policy Analysis Archives, 28(56). https://doi.org/10.14507/epaa.28.5026

Honan, E. (2010). Mapping discourses in teachers' talk about using digital texts in classrooms. Discourse: Studies in the Cultural Politics of Education, 31(2), 179-193. https://doi.org/10 $.1080 / 01596301003679701$

Jandrić, P., Knox, J., Besley, T., Ryberg, T., Suoranta, J., \& Hayes, S. (2018). Postdigital science and education. Educational Philosophy and Theory, 50(10), 893-899. https://doi.org/10.1080/ 00131857.2018.1454000

Jarke, J., \& Breiter, A. (2019). Editorial: the datafication of education. Learning, Media and Technology, 44(1), 1-6. https://doi.org/10.1080/17439884.2019.1573833

Kirschner, P. A., \& Kester, L. (2016). Towards a Research Agenda for Educational Technology Research. In N. Rushby \& D. W. Surry (Eds.), The Wiley Handbook of Learning Technology (pp. 523-541). John Wiley \& Sons, Inc. https://doi.org/10.1002/9781118736494.ch27

Kitchin, R., \& Dodge, M. (2011). Code/Space: Software and Everyday Life. MIT Press.

Knox, J. (2020). Artificial intelligence and education in China. Learning, Media and Technology, 45(3), 298-311. https://doi.org/10.1080/17439884.2020.1754236

Knox, J., Williamson, B., \& Bayne, S. (2020). Machine behaviourism: future visions of 'learnification' and 'datafication' across humans and digital technologies. Learning, Media and Technology, 45(1), 31-45. https://doi.org/10.1080/17439884.2019.1623251

Komljenovic, J. (2020). The future of value in digitalised higher education: Why data privacy should not be our biggest concern. Higher Education, 1-17. https://doi.org/10.1007/ s10734-020-00639-7

Lai, J. W., \& Bower, M. (2019). How is the use of technology in education evaluated? A systematic review. Computers \& Education, 133, 27-42. https://doi.org/10.1016/j.compedu.2019.01.010

Lewis, S. (2020). The turn towards policy mobilities and the theoretical-methodological implications for policy sociology. Critical Studies in Education, 0(0), 1-16. https://doi.org/10.1080/ 17508487.2020.1808499

Livingstone, S., Stoilova, M., \& Nandagiri, R. (2020). Data and Privacy Literacy. In D. Frau-Meigs et al. (Eds.), The Handbook of Media Education Research (pp. 413-425). John Wiley \& Sons. https://doi.org/10.1002/9781119166900.ch38

Loftus, M., \& Madden, M. G. (2020). A pedagogy of data and Artificial Intelligence for student subjectification. Teaching in Higher Education, 25(4), 456-475. https://doi.org/10.1080/ 13562517.2020 .1748593 
Marres, N. (2017). Marres, N: Digital Sociology: The Reinvention of Social Research. Wiley.

Pangrazio, L. (2021). Digital rights, digital citizenship and digital literacy: What's the difference. Journal of New Approaches in Educational Research, 10(1), 15-27. https://doi.org/10.7821/ naer.2021.1.616

Perrotta, C. (2021). Underdetermination, assemblage studies and educational technology: Rethinking causality and re-energising politics. Journal of New Approaches in Educational Research, 20(1), 57-66. https://doi.org/10.7821/naer.2021.1.638

Perrotta, C., Gulson, K. N., Williamson, B., \& Witzenberger, K. (2020). Automation, APIs and the distributed labour of platform pedagogies in Google Classroom. Critical Studies in Education, O(0), 1-17. https://doi.org/10.1080/17508487.2020.1855597

Player-Koro, C., Rensfeldt, A. B., \& Selwyn, N. (2018). Selling tech to teachers: education trade shows as policy events. Journal of Education Policy, 33(5), 682-703. https://doi.org/10.1080/ 02680939.2017.1380232

Regan, P. M., \& Khwaja, E. T. (2019). Mapping the political economy of education technology: A networks perspective. Policy Futures in Education, 17(8), 1000-1023. https://doi.org/10.1177/ 1478210318819495

Reich, J. (2020, 09 14). Ed-Tech Mania Is Back. Retrieved from https://www.chronicle.com/article/ ed-tech-mania-is-back

Savage, G. C. (2020). What is policy assemblage? Territory, Politics, Governance, 8(3), 319-335. https://doi.org/10.1080/21622671.2018.1559760

Sellar, S., \& Gulson, K. N. (2019). Becoming information centric: the emergence of new cognitive infrastructures in education policy. Journal of Education Policy, 0(0), 1-18. https://doi.org/ $10.1080 / 02680939.2019 .1678766$

Selwyn, N., Hillman, T., Eynon, R., Ferreira, G., Knox, J., Macgilchrist, F., \& Sancho-Gil, J. M. (2020). What's next for Ed-Tech? Critical hopes and concerns for the 2020s. Learning, Media and Technology, 45(1), 1-6. https://doi.org/10.1080/17439884.2020.1694945

Williamson, B. (2020). New digital laboratories of experimental knowledge production: Artificial intelligence and education research. London Review of Education. https://doi.org/10.14324/ LRE.18.2.05

Williamson, B., Eynon, R., \& Potter, J. (2020). Pandemic politics, pedagogies and practices: digital technologies and distance education during the coronavirus emergency. Learning, Media and Technology, 45, 107-114. https://doi.org/10.1080/17439884.2020.1761641

Williamson, B., \& Hogan, A. (2020). Commercialisation and privatisation in/of education in the context of Covid-19. Education International.

Youdell, D., \& Lindley, M. R. (2018). Biosocial Education: The Social and Biological Entanglements of Learning. Routledge.

Zawacki-Richter, O., Marín, V. I., Bond, M., \& Gouverneur, F. (2019). Systematic review of research on artificial intelligence applications in higher education - where are the educators? International Journal of Educational Technology in Higher Education, 16(1), 39-39. https://doi.org/10.1186/s41239-019-0171-0

Zhao, Y. (2017). What works may hurt: Side effects in education. Journal of Educational Change, 18(1), 1-19. https://doi.org/10.1007/s10833-016-9294-4 